\title{
$\mathrm{XX}$
}

Aus dem pharmakologisehen Institut zu Heidelberg.

\section{Ueber die Vertheilung des Chloralhydrats und Acetons im Organismus.}

\author{
Von \\ Dr. C. Archangelsky, \\ Assistent des pharmakologischen Instituts za Tomsk.
}

In den neueren Arbeiten über Narkose treten immer dentlicher die Beziehungen der narkotischen Wirkung zu einem specifischen Bindungsvermögen des Nervengewebes für die narkotisirenden Substanzen hervor. Das Studium der Vertheilung der Nareotica innerhalb des Organismus beansprucht deshalb erhöhtes Interesse.

Versehiedene Befunde und Ueberlegungen weisen darauf hin, dass die narkotischen Substanzen nicht etwa bei einer gleichmässigen Vertheilung im Organismus an den giftempfindlichen Elementen des Centralnervensystems die hervorstechensten Functionsänderungen veranlassen, sondern dass das Nervengewebe im Vergleiche zu anderen Geweben geradezu ein besonderes Anziehungsvermögen für diese Gifte besitzt. Einzelne hierauf bezügliche Feststellungen in der Gruppe des Alkohols und Chloroforms bildeten unter anderem den Ausgangspunkt der sehr ansprechenden Theorie der Alkoholnarkose; welche Hans Meyer in jüngster Zeit aufgestellt hat. Weiterbauend auf älteren Versuchen und Ueberlegungen (v. Bibra, Hermann u. A.) hat Hans Meyer ${ }^{1}$, auf ein Material zahlreicher neuer und wohlfundirter Thatsachen gestützt, der Vorstellung eine feste Grundlage gegeben, dass die narkotische Wirkung in der Alkohol- und Chloroformgruppe eine Function der Affinität dieser Gifte za den fettähnliehen Stoffen sei, die im Nervengewebe vorherrschen. In zahlreichen Versuchsreihen konnte Hans Meyer Beziehungen aufweisen, die zwischen der verhältnissmässigen

1) Hans Meyer, Zur Theorie der Alkohol-Narkose. Erste Mittheilung. Dieses Archiv. XLII. Bd. 1899. 
Wirkungsstärke verschiedener Narcotica und ihren mechanischen Affinitäten einerseits zu fettähnlichen Stoffen, andrerseits zu den anderen Körperbestandtheilen, hauptsächlich also zu Wasser, bestehen. Die relativen Wirkungsstärken fast aller untersuchten Substanzen verhielten sich wie die Theilungscoefficienten, welche ihre Vertheilung in einem Gemisch von Wasser und fettähnlichen Substanzen bestimmt.

Hans Meyer und Baum ${ }^{\text {) }}$ ermittelten den Theilungscoefficienten ausserhalb des Organismus in einem Gemisch von Wasser und Oel, als Vertreter fettähnlicher Substanzen. Die Wirkungsstärke der Narcotica wurde durch die Feststellung der geringsten molecularen Concentration gemessen, welche zur Narkose kleiner Versuchsthiere ausreichte, und zwar wurden diese Schwellenwerthe für den Eintritt der Wirkung an kleinen in der betreffenden Lösung schwimmenden Froschlarven oder Fischen bestimmt. Bei fast allen untersuchten Substanzen ergab sich ein auffallender Parallelismus der relativen Wirkungsstärke mit dem Theilungscoefficienten. Zu dem gleichen Resultate und damit zur Annahme eausaler Beziehungen zwischen Fettlöslichkeit und narkotischer Wirkung wurde auch Overton ${ }^{2}$ ) durch ungemein gründliche Untersuchungen an Pflanzenzellen, und besonders an kleinen in der narkotisirenden Lösung schwimmenden Thierchen geftihrt. Overton kam dadurch unabhängig von Hans Meyer zu den gleichen Ansehauungen.

Der Vergleich der Theilungscoefficienten zwischen Wasser und Oel mit der Wirkungsstärke war der einfachste Weg der Untersuchung, wenn man einen Ueberblick über die gesetzmässigen Beziehungen der Narkose und der Affinität zu fettartigen Bestandtheilen gewinnen wollte. Zur Ergänzung dieser Resultate ist aber auch ein zweiter Weg denkbar, nämlich der Vergleich der Wirkungsstärke der Narcotica an höheren Thieren mit dem Theilungscoefficienten ihrer Vertheilung zwischen Blut und Nervengewebe im Thierorganismus selbst. Dieser Weg ist jedoch ungleich complicirter und wird nur allmählich zum Ausbau der Theorie beschritten werden können. Denn ein Vergleich der Wirkungsstärke an höheren Thieren kann selbstverständlich nicht nach der Grösse der bei stomachaler oder subeutaner Einverleibung wirksamen Gaben durchgeführt werden, weil hier das Bild dureh die wechselnde Schnelligkeit der Resorption,

1) Fr. Baum, Zur Theorie der Alkohol-Narkose. Zweite Mittheilung. Dieses Archiv. XLII. Bd. 1899.

2) E. Overton, Studien über die Narkose. Jena 1901. 
durch Umwandlung, Deponirung und Aussebeidung des Narcoticums getrübt wird. Auch die Bestimmung der eben wirksamen Giftgabe bei intravenöver Injection umgeht nur die erste der genannten Fehlerquellen, die in der versehiedenen Resorptionsgeschwindigkeit liegt. Nur bei flüchtigen Giften wird an höheren Thierarten ein verwerthbarer Vergleich der Wirkungsstärke nach der Grösse der Giftconcentrationen möglich sein, da hier durch einen bestimmten Giftgehalt der Athmungsluft bekanntlich Aufnahme und Ausscheidung in ein constantes Gleichgewicht gesetzt werden können. Denselben Zustand erreichte Hans Meyer, indem er seine Versuchsthiere in einem Medium von bestimmtem Giftgehalt schwimmen liess; bei der Kleinheit der Kaulquappen konnte hierbei auch eine chemische Umwandlung der wirksamen Substanzen durch den Thierkörper in der kurzen Beobachtungszeit nicht in Betracht kommen. An höheren Thieren ist eine gleich exacte Dosirung nur bei flüchtigen Giften möglich (P. Bert, Cushny, Spenzer, Rosenfeld u. A.) und ist erst kürzlich durch Kionka ${ }^{1}$ ). zum Studium einschlägiger Fragen benutzt worden.

Bei den nicht flüchtigen Giften werden wir hingegen die relative Wirkungsstärke nicht aus der zugeführten Menge, sondern nur aus dem Giftgehalt des Blutes oder des Gehirnes erschliessen können, bei welchem ein bestimmter Grad der Narkose eintritt. Die Kenntniss dieser wirksamen Giftconcentrationen für eine grössere Reihe von Narcoticis der Alkohol- und Chloroformgruppe und ihr Vergleich mit den verschiedenen Theilungscoefficienten wird sadann auch bei böheren Versuchsthieren die Gesetzmässigkeiten erkennen lassen, welche zwischen der Wirkungsstärke narkotischer Substanzen und ihrer mechanischen Affinität zu fettartigen Stoffen besteht.

Weiterbin wird es auch von Bedeutung sein, bei ein und demselben Narcoticum den Giftgehalt des Centralnervensystems mit dem des Blutes zu vergleichen, um so den Theilungscoefficienten innerhalb des Organismus feststellen und mit jenem im Reagenzglase zwischen Oel und Wasser ermittelten in Parallele setzen zu können. Dabei ist keineswegs in allen Fällen eine vollkommene Uebereinstimmung der Theilungscoefficienten zwischen Gehirn und Blut und zwischen Oel und Wasser zu erwarten. Denn bei jener "A Assehüttelung" der Narcotica, die das Nervengewebe aus dem Blute vornimmt, kommen ja neben dem Lösungsvermögen fettartiger Substanzen auch zahlreiche andere Bestandtheile in Betracht, die auch ihrerseits

1) L. Kionka, Archive de Pharmakodynamie. VII. 1900. 
mechanische oder chemische Affinität zu den untersuchten Giften besitzen können. Wir haben deshalb in dem Organismus der höheren Versuchsthiere bei der Vertheilung der Narcotica auf ungleich complicirtere Verhältnisse zu rechnen, als in jenen Versuchsreihen an kleinen Wasserthieren, durch welche Hans Meyer und Overton der Theorie der Alkoholnarkose eine feste Grundlage gegeben haben.

Zu einer derartigen vergleichenden Betrachtung der Narcotica an böheren Thieren fehlen bisher die thatsächlichen Grundlagen. Man wird sich deshalb derzeit mit der Untersuchung begnügen müssen, in wie weit die Verhältnisse der Giftvertheilung im Einzelfalle den allgemeinsten Anforderungen der Theorie entspreehen. Es wird sich dabei im Wesentlichen um die Frage handeln, ob sich der Nachweis eines specifischen Anziehungsvermögens des Nervengewebes für narkotische Substanzen erbringen lässt. Von dieser Fragestellung gehen die folgenden Untersuchungen aus, in denen ich die Vertheilung des Chloralhydrats und Acetons im Organismus studirte.

Vor der Mittheilung der Ergebnisse seien die spärlichen bisher für die Vertheilung anderer Narcotica vorliegenden Kenntnisse kurz zusammengestellt. Es können dabei auch einige Thatsachen mit angeführt werden, welche über selective Aufnahme von nicht zur Fettreihe gehörigen Stoffen in das Nervengewebe ermittelt sind, obgleich in diesen Fällen die restituirbare Veränderung der Ganglienzellen vielleicht nicht von einer mechanischen Affinität zu fettartigen Substanzen, sondern zu anderen Bestandtheilen des Nervengewebes abhängt.

Ehrlich ${ }^{1}$ ) war wohl der Erste, welcher es versuchte, von den erörterten Gesichtspunkten aus die Vertheilungsgesetze toxischer Agentien im Körper festzustellen und die physiologischen Wirkungen mit der selectiven Aufnahme wirksamer Stoffe ins Nervengewebe in Beziehung zu bringen. Ehrlich fand bei seinen Farbstoffversuchen eine Reihe von Farbbasen und primären Farbsäuren "neurotrop", d. h. fähig, vom Hirngrau aufgenommen zu werden; hingegen erwies sich kein Farbstoff aus der Gruppe der Sulfosäuren als neurotrop und Ehrlich stellte diese Beobachtung mit der Thatsache in Parallele, dass auch für das Centralnervensystem toxisehe Stoffe, wie z. B. Alkaloide, ihre Giftigkeit durch Einführung der Sulfosäuregruppe einzubüssen pflegen. Auch sie verlieren dadurch ihren neurotropen Charakter.

1) P. Eibrlich, Zur therapeutischen Bedeutung der substituirenden Schwefelsäuregruppe. Therapeutische Monatshefte. 1887, März. 
Ehrlich sprach schon 1887 von einer "Aussehrittelung" der betreffenden Substanzen durch das Nervengewebe. In völlig klarer Weise hat bald darauf Hofmeister ${ }^{1}$ ) die Bedeutung der lockeren, leicht wieder lösbaren Bindung dureh mechanische Affinitäten für biologische Processe erörtert und im engsten Anschlusse an die von ihm entwickelten Vorstellungen hat dann $\mathrm{Poh}^{2}$ ) die für die physikalisch-ehemisehe Auffassung der Narkose grundlegende Thatsache festgestellt, dass die lockere Bindung des Chloroforms im Gehirn auf der mechanisehen Affinität der fettähnlichen Substanzen (Cholesterin, Leeithin, Cerebrin u. s. w.) beruht.

Pohl untersuchte in zwei Fällen, die wir hier heranziehen können, gleichzeitig den Gehalt des Blutes und Gehirns an Chloroform. In dem einen Falle erwies sich der procentisehe Gehalt des Gehirns bedeutend höher, als der des Blutes $(0,0418$ Proc. im Gehirn und 0,015 Proc. im Blut. Versuch 31. S. 252); im zweiten Falle lag der Chloroformgehalt des Gehirns etwas unter dem des Blutes $(0,036$ Proc. im Gehirn gegen 0,043 Proc. im Blate. Versuch 32 S. 252). Der erste Versuch zeigt jedenfalls, dass es Stadien der Narkose geben kann, in denen das Gehirn mehr Chloroform enthält, als das zuführende Blut. Andere Organe wurden in diesen Versuchen nicht auf ihren Chloroformgehalt geprüft, so dass ein Vergleich der versohiedenen Aufspeicherung des Giftes durch verschiedene Organe nieht durehfubrbar ist.

In der Vertheilung des Aethers im Thierkörper, welche $\mathrm{Frantz}^{8}$ ) unter Kunkel's Leitung studirte, ist der neurotrope Charakter des Nareoticums deutlich ansgeprägt. Bei vollständiger Narkose war der Procentgehalt des Aethers im Gehirn stets beträchtlich höher, als im Blute $(0,061$ Proc. im Gehirn gegen 0,037 Proe. im Blute im Durchschnitt der Versuche). Weiter ist aber aus der gleichzeitigen Bestimmung in der Leber zu entnehmen, dass sich das Gehirn aus dem umspülenden Blute stärker mit Aether anzureichern vermag, als andere, und zwar keineswegs fettarme Organe; denn das Gehirn enthielt immer weit mehr Aether als die Leber, ja der Aethergehalt der Leber blieb sogar hinter dem des Blutes zurüek $(0,015$ Proc. in der Leber gegen 0,037 Proc. im Blute), offenbar

1) Fr. Hofmeister, Zur Lehre von der Wirknng der Salze. 6. Mittheilung. Dieses Archiv. Bd. XXVIII. 1891. S. 236.

2) J. Pohl, Ueber Aufnahme und Vertheilung des Chloroforms im thierischen Organismus. Dieses Archiv. Bd. XXVIII. 1891.

3) R. Frantz, Ueber das Verhalten des Aethers im thier. Organismus. Inang. Dissertation Würzburg 1895. 
weil das Blut nicht bloss als indifferenter Aetherträger fungirt, sondern die rothen Blutkörperchen, wie es seit Sehmiedebergi vom Chloroform bekannt ist, auch Aether zu binden vermögen.

Für den Alkohol liegt schon die alte Angabe ron Lallemand, Perrin und Duroy ${ }^{2}$ ) vor, dass Gehirn und Leber bei der Vertheilung des Weingeistes im Organismus weit mehr Gift enthielten, als die gleiche Menge Blut. Doch hat Schulinus ${ }^{3}$ ) gezeigt, dass diese Ergebnisse mit unzureichenden Methoden erlangt sind. Er "selbst fand zwar auch im Beginn der Alkoholresorption das Gehirn etwas alkoholreicher, als das Blut, konnte aber im Ganzen doch nur ein sehr weehselndes Verhalten constatiren. Neuerdings hat Grehant ${ }^{4}$ ) diese Frage mittelst einer sorgfältig ausgearbeiteten Methode wieder aufgenommen und in einem Falle bei der Bestimmung in den Geweben eines an aouter Vergiftung verendeten Hundes im Gehirn 0,41 Proc. gefunden, während die Muskeln 0,33 Proc., Leber 0,325 Proc. und die Niere 0,39 Proc. enthielten. Damit stimmt die von Pauly und Bonne ${ }^{5}$ vorgenommene Untersuchung der Organe eines anf der Höhe schwerer Alkoholvergiftung Verstorbenen überein, bei der sich im Blute 0,33 Proc., in der Leber 0,21 Proc, im Gehirn aber 0,47 Proc. fanden. Jedesfalls kann demnach in gewissen Stadien der Alkoholnarkose das Gehirn reicher an Gift sein, als andere Organe.

Weiter sei dann noch das Verhalten des Broms im Organismus angeführt. Nach den eingehenden Versuchen von Fessel ${ }^{6}$ ) häuft sich dasselbe gleichfalls im Gehirn an, denn auch in der blutfreien Gehirnmasse fand sich eine nicht unbeträchtliche Menge von Brom vor, während die Leber davon frei war. Dadurch wird eine frühere Angabe von Doyon bestätigt, der im Gehirn einer Epileptischen weit mehr Bromkalium bestimmte, als in der Leber.

Der kurze Ueberblick zeigt, dass wir über die Vertheilung flüchtiger Substanzen aus der Gruppe des Alkohols und Cbloroforms einige, wenn auch spärliche Kenntnisse besitzen. Wir haben die-

1) O. Schmiedeberg, Archiv der Heilkunde. 1867. S. 273.

2) Lallemand, Perrin u. Duroy, L'Union médicale 1859 und Gazette médicale de Paris 1861. (citirt nach Schulinus.)

3) H. Schulinus, Ueber die Vertheilung des Weingeistes im thierischen Organismus. Inaug. Dissertation Dorpat 1865 (unter Buchheim).

4) Gréhant, Comptes reud. 1899. S. 746.

5) Pauly u. Bonne, Lyon médicale 1897. Citirt nach Heffter in Schmidt's Jahrbüchern. Bd. 25i.

6) Fessel, Münchener medicinische Wochenschrift 1899. Nr. 39. 
Ueber die Vertheilung des Chloralhydrats und Acetons im Organismus. 353

selben durch das Studium der Acetonvertheilung zu vervollständigen gesucht. Ueber die Vertheilung nicht flüchtiger Nareotica der Fettreihe liegen bisher keinerlei Erfahrungen vor. Ich folgte daher gerne der Anregung, die nachfolgende quantitative Bestimmung' des Chloralhydrats in Blut und Geweben auszuarbeiten und mittelst derselben die Vertheilung dieses wiehtigen Hypnoticums zu studiren.

Methode der Bestimmung von Chloralhydrat in Blut und Geweben.

Um das Chloralhydrat zum Zwecke quantitativer Bestimmung vorerst von zahlreichen anderen Stoffen abzutrennen, wurden Blut und Organe unter Zusatz etwa des halben bis gleichen Gewichtes 20 proc. Phosphorsäure mit Wasser destillirt. Nach 3-stündiger Destillation von $0,37 \mathrm{~g}$ Chloralhydrat mit $200 \mathrm{~g}$ Wasser war im Ruickstand kein Chloralhydrat mehr nachweisbar. Aber anch bei der Destillation von Blut und Organen geht das Chloralhydrat mit den Wasserdämpfen nach 5- bis 10-stündiger Destillation so vollständig über, dass in den zuletzt überdestillirten Antheilen der empfindliche qualitative Nachweis versagt und eine zugesetzte Chloralhydratmenge sich quantitativ im Destillate wieder bestimmen lässt. Die Flüchtigkeit des Chloralhydrats mit Wasserdämpfen ist demnach zur Abscheidung ron anderen nicht flüchtigen Substanzen eine genügende.

Bei der sauren Destillation wird das Chloralhydrat schon theilweise zersetzt. Abgesehen von fremden Substanzen findet sich somit Chloralhydrat neben seinen Zersetzungsproducten im Destillate vor. Nach vollständiger Spaltung mittelst Natronlange kana es darin aus der Menge eines dieser Spaltungsproducte bestimmt werden. Auch alle bisherigen quantitativen Bestimmungsversuche gehen von einer Spaltung des Chloralhydrats aus, da es bekanntlich nicht gelingt, die Substanz selbst in Form einer gut charakterisirten Verbindung abzuscheiden. Beide Spaltungsproducte, Chloroform und Ameisensäure, sind zur quantitativen Bestimmung herangezogen worden.

Nachdem bereits Hammarsten ${ }^{1}$ ) das Chloralhydrat im Blute qualitativ dadurch sichergestellt hatte, dass er es zunächst zerlegte und nach weiterer Zersetzung des entstandenen Chloroforms Chlor nachwies, haben Vitali und Tornani²) die Bestimmung des

1) Hammarsten, Deutsehe Klinik 1870.

2) Vitali u. Tornani, Annal. di chim. med. e farmac. IV. Citire nach Maly's Jahresb. Bd. 15.

A rchiv f. experiment. Pathol, u. Pharmakol. XLVI. Bd. 
Chloroforms als Methode zum Nachweis des Chloralhydrats in Geweben und Blut angewandt. Auch Bongers') benutzte den Naehweis der Chloroformabspaltung bei alkaliseher Destillation zur Feststellung der theilweisen Ausseheidung des Chloralhydrats in den Magen. Die quantitative Bestimmung aus der Menge des abgespaltenen Chloroforms erseheint aber deshalb weniger geeignet, weil bei der Zersetzung des Chloralhydrats mit Natronlauge das entstehende Chloroform theilweise bereits weiter gespalten werden kann. Das beweisen die Beobachtungen von $\mathrm{D}$ es $\mathrm{grez}$ und $\mathrm{Niclou}{ }^{2}{ }^{2}$, welche bei der Spaltung des Chloralhydrats durch Alkalien neben Chloroform auch Chlor entstehen sahen, das sich als Chlornatrium in der Flüssigkeit fand.

Zum Zwecke der quantitativen Bestimmung erscheint es deshalb aussichtsvoller, von dem andern Spaltungsproducte, der Ameisensäure, auszugehen. Freilich kann man in physiologischen Versuchen die entstandene Ameisensäure nicht einfach titrimetriseh bestimmen, wie es V. Meyer und $\mathrm{Haffter}{ }^{3}$ ) für reines Chloralhydrat empfohlen haben. Denn nach diesen Autoren fallen die Bestimmungen erst bei Anwendung etwas grösserer Mengen genau aus. Hingegen erwies sich für den Zweck, anch die kleinsten Mengen der aus der Spaltung hervorgegangenen Ameisensäure zu ermitteln, die Scala'sche Methode ${ }^{4}$ ) der Ameisensäurebestimmung brauchbar, bei der man nach Zusatz von Sublimat das entstandene Calomel wägt. Diese Methode hat bereits $\mathrm{Pohl}^{5}$ ) für die Bestimmung der Ameisensäure im Harn und in Organen ausgearbeitet und dabei gute Resultate erzielt.

Wir haben somit im Destillate die vollständige Spaltung des Chloralhydrats in Chloroform und Ameisensäure vorgenommen und die gebildete Ameisensäure nach Scala quantitativ bestimmt.

In wässrigen Lösungen von Chloralhydrat oder in Destillaten aus denselben ergiebt diese Methode derart scharfe Resultate, wie wir sie bei der Bestimmung anorganischer Substanzen verlangen. Die Lösung einer abgewogenen Menge von Chloralhydrat wurde mit überschüssiger Normal-Natronlange auf dem Wasserbade bis auf wenige ccm eingeengt, die Lauge dann mit Essigsäure genau neu-

1) Bongers, Ueber die Ausscheidung körperfremder Stoffe in den Magen. Dieses Archiv. Bd. XXXV.

2) Desgrez u. Nicloux, Comptes rend. de la soc. de Biologie. 1897 u. 1898

3) V. Meyer u. Haffter, Ber. d. d. chem. Ges. Bd. VI. S. 600.

4) Scala, Chem. Berichte. Bd. 23. Ref. 599.

5) Pohl, Dieses Archiv. Bd. XXXI. 
tralisirt. Nach Zusatz der gleichen Menge concentrirter Sublimatlösung und 4-5-stündigem Erhitzen auf dem Wasserbade lässt man einige Stunden stehen, filtrirt den entstandenen Calomelniederseblag auf ein gewogenes Filter, wäscht bis zur Cblorfreiheit aus, trocknet den Calomelniedersehlag bis zur Gewichtsconstanz und bringt ihn zur -Wägung. Dureh Multiplication des gewogenen Gewichtes an Calomel mit dem Factor: 0,3510 erbält man die gefundene Menge Chloralhydrat. Die folgenden Beispiele zeigen, dass die Methode in reinen Chlorallösungen scharf übereinstimmende Werthe liefert.

\begin{tabular}{lccc}
\multicolumn{2}{c}{ Chloralhydrat verlangt } & Chloralhydrat gefunden & Differeuz \\
1. & 0,1682 & 0,1674 & $-0,0008$ \\
2. & 0,0675 & 0,0682 & $+0,0007$ \\
3. & 0,0550 & 0,0535 & $-0,0015$
\end{tabular}

Mit dem Chloralhydrat gehen bei saurer Destillation natürlich noch andere flüchtige Körper, insbesondere Fettsäuren über, und es fragt sich, in wie weit dieselben die Bestimmung stören. Im Destillat aus Blut sind solche störende Verunreinigungen niemals in erheblichen Mengen enthalten und in dem farblosen und klaren Destillate fallen die Bestimmungen befriedigend aus. Weniger gtinstig verhalten sich die aus Leber und Gehirn gewonnenen Destillate. Hier gehen andere Substanzen mit über, welehe nach der Behandlung mit Natronlauge beim Zusatz von Sublimat flockige Niederschläge geben, welche die Wägung des gleichzeitig entstandenen Calomelniederschlags unmöglich machen. Destillirt man aber die aus diesen Organen. gewonnenen Destillate unter Zusatz von Phosphorsäure und besonders bei guter Kühlung noch einmal, so erhält man farblose und wenig getribte Destillate, in welchen nach dem Abfiltriren einer geringen flockigen Trübung die Bestimmung der Ameisensäure nach der Zersetzung gut ausgeführt werden kann. Die Methode ist sonach auch in den Destillaten von Blut und Organen anwendbar.

Die Bestimmung des Chloralhydrats aus der abgespaltenen Ameisensäure nach der Scala'sehen Methode hat aber noch die zweite Voraussetzung, dass die in normalen, von Chloralhydrat freien Geweben enthaltene Menge von Ameisensäure oder anderen bei gleicher Behandlung Sublimat reducirenden Substanzen eine so geringe ist, dass sie bei der Bestimmung vernachlässigt werden konnte. In dieser Richtung wurden neben Blut nur Gebirn und Leber geprüft. Dabei erwies sich die in $40-50 \mathrm{~g}$ Blut enthaltene Menge von Ameisensäure oder anderen flüchtigen Verbindungen, die 
sich nach der Behandlung mit Natronlauge wie Ameisensäure verhalten, in mehreren Fällen als so gering, dass eine Wägung des erhaltenen Niederschlages unmöglich war oder nur Zehntel Milligramme ergab. Nur in einigen Versuchen, vielleicht bei stärkerer Concentration des Riickstands im Destillationskolben, stieg die Calomelmenge auf Werthe, die auf Chloralhydrat umgerechnet 2--6 mgr auf 100 Blut vortäuschen würden. Bei dem erheblichen Gehalt, den das Blut nach Chloralhydratzufuhr an dem Narcoticum zeigt, kommt diese geringe Menge, die den Chloralhydratwerth fälschlich vergrössern könnte, nicht in Betracht. Auch im Gehirn sind die nach zweimaliger Destillation aus dem Organ selbst gewonnenen Calomelniederschläge ungemein gering und übersteigen nicht 2 bis $3 \mathrm{mgr}$ pro 100 Organ. In der Leber hingegen können diese Werthe etwas höher ausfallen und bis $8 \mathrm{mgr}$ pro 100 betragen.

Diesen Vorversuchen entsprach das Resultat von methodischen Versuchen, in denen grewogene Mengen Chloralbydrat zu Blut und Organen zugesetzt und aus der abgespaltenen Ameisensäure in den Destillaten in genügender Uebereinstimmung wiederbestimmt werden konnten.

Methodische Versuche.

\begin{tabular}{|c|c|c|c|c|c|}
\hline Versuch & $\begin{array}{l}\text { Gewicht } \\
\text { des Organs }\end{array}$ & $\begin{array}{c}\text { Chloralhydrat } \\
\text { zugesetzt }\end{array}$ & $\begin{array}{c}\text { Chloralhydrat } \\
\text { gefunden }\end{array}$ & Differenz & Bemerkungen \\
\hline $\begin{array}{l}1 . \\
2 . \\
3 . \\
4 . \\
5 . \\
6 . \\
7 . \\
8 .\end{array}$ & $\begin{array}{l}43 \mathrm{~g} \text { Blut } \\
62== \\
56== \\
50== \\
20 \mathrm{~g} \text { Gehirn } \\
56== \\
50 \mathrm{~g} \text { Leber } \\
58==\end{array}$ & $\begin{array}{l}0,0450 \mathrm{~g} \\
0,1935= \\
0,0954= \\
0,0540= \\
0,0680= \\
0,1205= \\
0,0540= \\
0,0785=\end{array}$ & $\begin{array}{l}0,0433 \mathrm{~g} \\
0,1942= \\
0,0949= \\
0,0465= \\
0,0688= \\
0,1226= \\
0,0548= \\
0,0828=\end{array}$ & $\begin{array}{l}-1,7 \mathrm{mg} \\
+0,7= \\
-0,5= \\
-8,0= \\
+0,8= \\
+2,1= \\
+0,8= \\
+4,3=\end{array}$ & $\begin{array}{c}\text { nur } 3 \text { Stunden } \\
\text { destillirt! }\end{array}$ \\
\hline
\end{tabular}

Wie aus der Tabelle ersichtlich, ist die Uebereinstimmung bei Zusatz zu Blut und Gehirn eine befriedigende; nur Versuch 4 zeigt eine grössere Differenz, weil hier die Zeit der Destillation nur auf 3 Stunden ausgedehnt wurde. Bei Zusatz zur Leber (8) ergiebt sich ein etwas zu grosser Fehler in Uebereinstimmung mit der grösseren Menge der aus dem Organe selbst stammenden Ameisensäure. Die aus der Leber erhaltenen Zahlen sind deshalb nur als Maximalzahlen anzusehen. Im Blute giebt die Methode, bei genügender Dauer der Destillation, recht gute Resultate; auch für Gehirn und Leber erscheint sie zur Beantwortung toxikologischer Fragen hinreichend genau.

Die in den folgenden Versuchen angewandte Bestimmung des 
Ueber die Vertheilung des Chloralhydrats und Acetons im Organismus. 357

Chloralhydrats bestand demnach in Destillation des Chloralhydrats, Zerlegung der Substanz mit Natronlauge, Oxydation der entstandenen Ameisensäure dureh Sublimat und Wägung des Calomels.

Im Einzelnen wurde wie folgt vorgegangen: Die Organe wurden mit etwa dem gleichen Gewichte 20\% Stunden destillirt, bis im letzten Destillate nach Zusatz von Natronlauge und Sublimat und Erhitzen der Probe anch nach längerem Stehen keine Trübung mehr entstand. Dieser qualitative Nachweis der letzten Spuren von übergegangenem Chloralhydrat oder Ameisensăure erwies sich uns als ungemein empfindlich; noch 0,00006 oder $0 / 100 \mathrm{mg}$ Chloralhydrat geben bei dieser Behandlung in $5 \mathrm{ccm}$ Wasser noch eine sichtbare Trübung. Das Destillat muss farblos und klar sein; gelb gefärbte oder stärker getrübte Destillate müssen nochmals mit Phosphorsäure destillirt werden. Bei der Bestimmung in Gehirn und Leber ist stets eine solche zweite Destillation mit Zusatz von etwa $10 \mathrm{ccm} 20$ proc. Phosphorsäure und mit guter Kühlung nothwendig. Das Destillat wird nach dem $A b$ filtriren einer geringen flockigen Trübung, die sich beim Stehen meist bildet, mit 30 bis $50 \mathrm{ccm}$ Normal-NaOH zersetzt, indem man auf dem heissen Wasserbade auf 20 bis $50 \mathrm{ccm}$ einengt. Dann wird genan mit Essigsäure neutralisirt, wobei Kohlensäure entweicht, worauf bei der genauen Neutralisation Rücksicht zu nehmen ist. Nach dem Filtriren wird die gleiche Menge gesättigter Sublimatlösung hinzugefügt und 1 bis 2 Stunden stehen gelassen. $\mathrm{Da}$ in derart verdünnten Lösungen die Ameisensäure auch nach 5- bis 6-stündigem Stehen mit Sublimat in der Kälte noch keine Niederschläge entstehen lässt, so können flockige Niederschläge, die sich bei 1- bis 2 stündigem Stehen schon in der Kälte häufig bilden, ohne Weiteres abfiltrirt werden. Der schwere Calomelniederschlag entsteht ejst beim Erwärmen; man lässt 5 bis 6 Stunden auf dem kochenden Wasserbade stehen und einige Stunden lang erkalten. Endlich wird der Calomelniederschlag gesammelt, ausgewaschen, getrocknet und gewogen. Durch Multiplication mit dem Factor: 0,3510 erhält man die gefundene Menge Chloralhydrat.

\section{Chloralhydratversnehe.}

Die Versuche wurden grössten Theils an Hunden, nur zwei Versuche an Kaninchen ausgefülrt. Die mehrmalige Entnahme von Blutproben während der verschiedenen Stadien einer Vergiftung hatten zum Ziele, den Parallelismus des Giftgehalts im Blute mit der Schwere der Vergiftungssymptome zu verfolgen und so die toxikologisch und gerichtlich nicht unwichtige Frage zu beantworten, bei welehem Gehalt des Blutes an Chloralhydrat eine tiefe Narkose eintritt und von welcher Grenze an das Leben bedroht ist. Zu Ende des Versuchs wurden die Thiere in verschiedenen Stadien der Vergiftung vollständig verblatet und durch die Bestimmung in Blut, Gehirn und Leber ein Aufschluss darüber gewonnen, wie das. 
Narcoticum zwischen diesen Geweben vertheilt war. Dabei konnte es nicht beabsichtigt werden, einen vollständigen Ueberblick über den Verbleib des Giftes im Körper zu gewinnen; die Versuche geben vielmehr nur Aufschluss iber den Giftgehalt des Blutes, des Gehirns und der Leber bei leichterer und sobwerer Chloralhydratvergiftung. Bei dem gewonnenen Resultate blieb anch das Umwandlungsproduct des Chloralhydrats im Organismus, der Trichloräthylalkohol und sein Paarling, die Urochloralsäure, unberüeksichtigt. Darauf konnte verzichtet werden, weil die Fragestellung vor allem Gehalt und Vertheilung des wirksamen Agens in Blut und Organen ins Ange fasste, die Urochloralsänre aber sich in den Versuchen von $\mathrm{K}_{\mathrm{u}} \mathrm{z}^{1}{ }^{1}$ ) als physiologisch unwirksam erwiesen hat.

Zunächst seien die wichtigsten Daten ans den Versuchsprotokollen im Auszug wiedergegeben.

Versuch I. Kaninchen von $2150 \mathrm{~g}$ erhält 3 Uhr 30 Min. $1,6 \mathrm{~g}$ Chloralhydrat in $50 \mathrm{ccm}$ Wasser per os.

Nach 50 Min. tiefe Narkose, der Cornealreflex ist verschwunden, die Respiration ist aber noch gut. 55 Min. nach der Vergiftung wird das Thier verblutet.

Nach der Verblutung enthalten:

$$
\begin{array}{ccc}
75,5 \mathrm{~g} \text { Blut }-0,108 \mathrm{~g} \text { Chlorallydrat } & =0,143 \text { Proc. } \\
51,8 \text {, Leber - } 0,0136 " & \# & =0,026 " \\
8,0 \% \text { Gehirn - } 0,005 " & " & =0,10 \% "
\end{array}
$$

Versuch II. Kaninchen von $1700 \mathrm{~g}$ erhält 10 Uhr 35 Min. $1,4 \mathrm{~g}$ Chloralhydrat in $45 \mathrm{cem}$ Wasser per os.

50 Minuten daranf wird die Respiration in tiefer Narkose ungenügend, sehr langsam. In diesem Zustand wird das Thier verblutet.

Nach der Verblatung enthalten:

$$
\begin{array}{ccc}
47,0 \mathrm{~g} \text { Blut }-0,0734 \mathrm{~g} \text { Chloralhydrat } & =0,156 \text { Proc. } \\
47,5 \text { " Leber }-0,0057 " & \text { " } & =0,019 ", \\
7,2, \text { Gehirn }-0,086, & , " & =0,11 "
\end{array}
$$

Versuch III. Hund von 4,5 Kilo. 3 Uhr 20 Min. Einführung von 2,25 g Chloralhydrat in verdünnter Lösung per os.

Nach 50 Minuten sehr tiefe Narkose, Cornealreflex völlig verschwunden, aber noch selbstständige Athmung, die eben zu versagen droht.

Nach der Verblatung in diesem Zustande enthalten (nach Ausspülung der Organe mit NaCl-Lösung):

$\begin{array}{rlrl}116 \mathrm{~g} \text { Blut }-0,136 \mathrm{~g} \text { Chloralhydrat } & & =0,11 \text { Proc. } \\ 84 \text { "Leber - } 0,0039 " & " & =0,0047 " \\ 68, \text { Gehirn - 0,0252" } & ", & =0,039 "\end{array}$

Versuch IV. Hand von 8,9 Kilo. 11 Ubr 5 Min. subcutane Injection von $4,0 \mathrm{~g}$ Chloralhydrat in $40 \mathrm{ccm}$ Wasser.

Nach einer Stunde wird das Thier zur Verblatung aufgebunden. Unmittelbar vor der Verblutng tritt Athmungsstillstand ein.

1) $\mathrm{Külz}$, Pflüger's Archiv. XXVIII. Bd. 1882. 
Ueber die Vertheilung des Chloralhydrats und Acetons im Organismus. 359

Nach der Verblutung enthalten:

\begin{tabular}{|c|c|c|c|c|}
\hline $144 \mathrm{~g}$ Blut & $-0,181$ & g Chloralhydrat & $=0,12$ & Proc \\
\hline 92 , Leber & $-0,0047$ & $\eta$ & $=0,005$ & 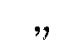 \\
\hline 7,6, , Gehirn & $-0,024$ & $"$ & $=0,042$ & \\
\hline 5,0, Milz & $-\quad 0$ & $"$ & $=0$ & 77 \\
\hline min & 0,059 & $n$ & & \\
\hline
\end{tabular}

Versuch V. Hund von 5,9 Kilo. 3 Uhr 25 Min. bis 3 Uhr 35 Min. werden langsam $1 \mathrm{~g}$ Chloralhydrat in 5 procentiger Lösung in die Vena jugularis injicirt. Während des langsamen Einlanfs erfolgt 3 Uhr 35 Min. Respirationsstillstand. Es wird künstliche Athmung eingeleitet und 5 Minuten nach dem Respirationsstillstand Blut entnommen.

Blut I: in $44 \mathrm{~g}$ Blut werden $0,053 \mathrm{~g}$ Chloralhydrat gefunden $=0,12$ Proc.

35 Minuten nach Beendigung der intravenösen Injection athmet der Hund wieder selbstständig. Daraf Verblutung vorgenommen.

Nach der Verblutung enthalten:

$43,7 \mathrm{~g}$ Blut II - 0,013 g Chloralhydrat

45,2 , Leber $-0,015, "$

46,5, Gehirn - 0,0194, ,

$=0,031$ Proc.

$=0,03$

$=0,042 "$

Versuch VI. Hund von 7,7 Kilo. 3 Uhr 25 Min. Einführung von $3,85 \mathrm{~g}$ Chloralhydrat in verdünnter Lösung in den Magen.

Nach 20 Minuten tiefe Narkose, nach 30 Min. 1. Blutentuahme bei erhaltenem Cornealreflex und guter Athmung.

Blut I: in $20 \mathrm{~g}$ Blut werden $0,010 \mathrm{~g}$ Chloralhydrat gefunden $=0,05$ Proc.

Nach 1 Stunde wird bei gleich tiefer Narkose eine 2. Blutentnahme vorgenommen.

Blut II: in $20,5 \mathrm{~g}$ Blut werden $0,0104 \mathrm{~g}$ Chloralhydrat gefunden $=0,05$ Proc.

11/2 Stunden nach der Vergiftung ist der Cornealreflex geschwunden. $1 / 2$ Stunde darnach 3. Blutentnahme.

Blut III: in $30,0 \mathrm{~g}$ Blut werden $0,0228 \mathrm{~g}$ Chloralhydrat gefunden $=0,076$ Proc.

$21 / 2$ Stunden nach Einführung des Gifts ist der Cornealreflex wieder deatlich, es wird 4 . Blutentnahme vorgenommen.

Blut IV: in 21,0 $\mathrm{g}$ Blut werden $0,0148 \mathrm{~g}$ Chloralhydrat gefunden $=0,07$ Proc.

3 Stunden nach der Vergiftung beginnt das Thier zu erwachen winselt ete. etc. Das Thier wird verblutet.

Nach der Verblutung enthalten:

$23 \mathrm{~g}$ Blut $\mathrm{V}-0,011 \mathrm{~g}$ Chloralhydrat $\quad=0,048$ Proc.

52 "Gehirn - 0,035" " =

Versuch VII. Hund von 8,9 Kilo. 3 Uhr 30 Min. subcutane Injection von $4,45 \mathrm{~g}$ Chloralhydrat in $45 \mathrm{ccm}$ Wasser.

40 Minuten darauf wird das Thier in tiefer Narkose, aber bei selbstständiger Athmung verblutet. 
Nach der Verblutung enthalten:

$43,5 \mathrm{~g}$ Blut $\quad-0,0204 \mathrm{~g}$ Chloralhydrat

124,0, , Leber

$-0,0422$,

53,0, Gebirn

$-0,0233$,

8,0, Rückenmark - 0,01 "

$=0,047$ Proc.

$=0,033$

$=0,044$,

$=0,12 \quad$

Versuch VIII. Hund 6,4 Kilo. Langsamer intravenöser Einlauf

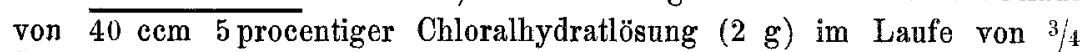
Stunden; 4 Uhr 50-5 Uhr 35 Min.

Bei Beendigung des Einlaufs noch 16 Respirationen in der Minute. 2 Minuten darauf tritt Athmungsstillstand ein; es wird sogleich die 1. Blutprobe entnommen und künstliche Athmung eingeleitet.

Blut I: in $40 \mathrm{~g}$ Blut finden sich $0,0452 \mathrm{~g}$ Chloralhydrat $=0,113$ Proc.

$1 / 2$ Stunde nach Beendigung der Giftzufuhr wird eine 2. Blutprobe entnommen.

Blut II: in $43,7 \mathrm{~g}$ Blut finden sich $0,0210 \mathrm{~g}$ Chloralhydrat $=0,048$ Proc.

22 Minuten darnach athmet der Hund wieder selbstständig, die Reflexe sind zurückgekehrt und das Thier wird verblutet.

Nach der Verblutung enthalten:

$32,9 \mathrm{~g}$ Blut $\quad-0,0115 \mathrm{~g}$ Chloralhydrat $\quad=0,035$ Proc.

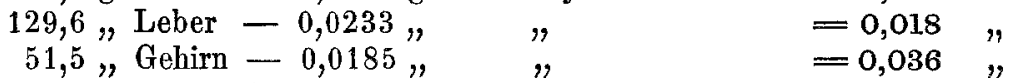

Versuch IX. Hund 7,5 Kilo. Vorher $6 \mathrm{mg}$ pro Kilo Morphin. Langsamer Einlauf von ca. 20 cem 5 procentiger Chloralhydratlösung $(1 \mathrm{~g})$ im Laufe von 15 Minuten in die Vena jugularis. Die Carotis ist mit dem Kymographion verbunden.

Bei einer Druckherabsetzung von 120 auf $50 \mathrm{~mm} \mathrm{Hg}$ ist der Cornealreflex eben verschwunden. Zu diesem Zeitpunkt 1. Blatentnahme.

Blut $\mathrm{I}:$ in $47,3 \mathrm{~g}$ Blut finden sich $0,0265 \mathrm{~g}$ Chloralhydrat $=0,056$ Proc.

Nach weiterer langsamer Zufuhr von $8 \mathrm{ccm} 5$ proc. Chloralhydrat sistirt die Athmung nach weiteren 11 Minuten. Darauf Blutentnahme.

Blut II: in $9,5 \mathrm{~g}$. Blut finden sich $0,0070 \mathrm{~g}$ Chloralhydrat $=0,074$ Proc.

Versuch X. Hund 5,3 Kilo. Einführung von $3 \mathrm{~g}$ Chloralhydrat per Schlundsonde. Da nach etwa 30 Minuten Erbrechen erfolgt, so ist die wirklich resorbirte Menge nicht festzustellen. In tiefer Narkose wird 1 Stunde nach der Vergiftung 1. Blutprobe entnommen unmittelbar nach dem Erlöschen des Cornealreflexes.

Blut I: in $30 \mathrm{~g}$ Blut finden sich $0,021 \mathrm{~g}$ Chloralhydrat $=0,07$ Proc.

$11 / 2$ Stunden danach ist das Thier wieder aus der Narkose erwacht. Es wird verblutet.

Nach der Verblutung enthalten:

37 g Blut II $=0,0074 \mathrm{~g}$ Chloralhydrat $\quad=0,02$ Proc.

104 "Leber $=0,0208 " \quad " \quad=0,02 "$

$41,3 "$ Gehirn $=0,0083 " \quad$ " $=0,02 "$ 
Ueber die Vertheilung des ChJoralhydrats und Acetons im Organismus. 361

Die wichtigsten Resultate der Versuche können in der folgenden Tabelle übersichtlich zusammengefasst werden.

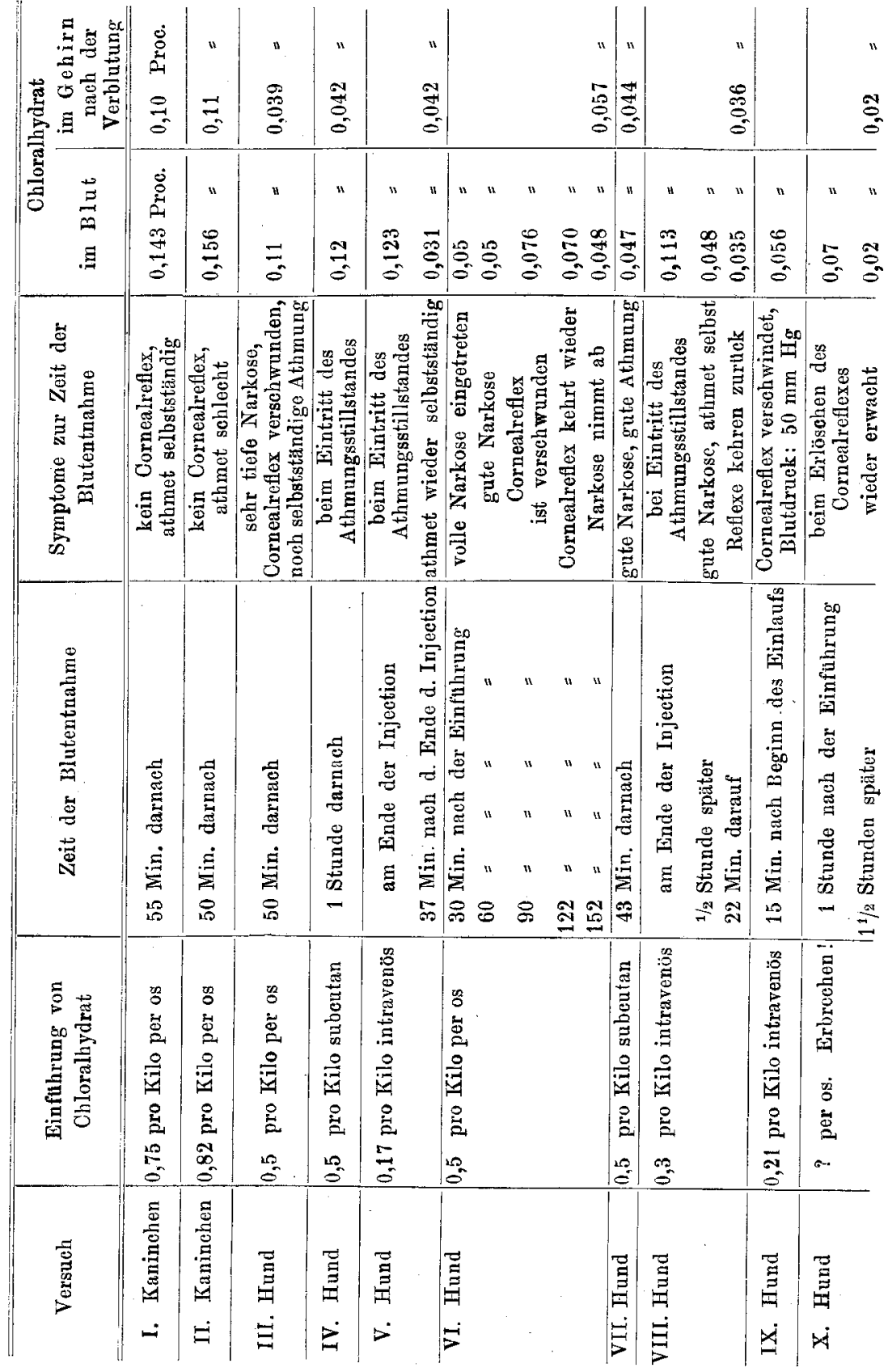


Aus den Versuchen ist vor allem zu entnehmen, dass der Chloralhydratgehalt des Gehirns während einer tiefen Narkose bei der gleichen Thierart innerhalb enger Grenzen schwankt. Beim Kaninchen ist er ungleich höher, mehr als doppelt so hoch, wie beim Hunde, ein Verhalten, in dem wir wohl den Ausdruck für die gering'ere Empfindlichkeit des Kaninchens dem Gifte gegenüber sehen dürfen. Beim Hunde fand sich fast in allen Fällen, die während der Narkose verblutet wurden, im Gehirn eine Giftconcentration von 0,036 bis 0,044 Proc. vor; nur nach der besonders langdauernden Vergiftung in Versuch VI stieg der Chloralhydratgehalt auf 0,057 Proc. Bei einem Gehalte von 0,02 Proc. im Gehirn war das Versuchsthier in Versuch $\mathrm{X}$ schon wieder aus der Narkose erwacht.

Da das Centralnervensystem um so reicher an Gift sein kann, je mehr das gemeinsame Giftreservoir aller Organe, das Blut davon enthält,'so hängt der Chloralhydratgehalt des Gehirns indirect von dem des Blutes ab. Fuir das Blut aber lässt sich dureh die Entnahme mehrerer Blutproben im Verlaufe einer Vergiftung feststellen, bei welchem Giftgehalte die tiefe Narkose und die wichtigsten Symptone der Vergiftung eintreten. Bei Hunden bewegen sich nun die während tiefer, das Leben aber noch nicht bedrohender Narkose im Blut erhaltenen. Werthe zwischen 0,031 bis 0,076 Proc.; im Durchschnitt beträgt der Chloralgehalt des Blutes bei tiefer Narkose somit 0,05 Proc. So finden wir in Vers. V b 0,031 Proc. und in Vers. VIII b 0,035 Proc. nach intravenöser Zufuhr, in Vers. VII 0,047 Proc. nach subcutaner Einführung während guter Narkose und bei selbstständiger Athmung. Auch bei allmählicher Resorption von $0,5 \mathrm{~g}$ per os war in Vers. VI a gleichfalls bei 0,05 Proc. im Blute tiefe Narkose eingetreten. Nach der langdauernden Narkose im selben Falle findet sich bei einem Gehalte von 0,048 Wiederauftreten von Schmerzäusserungen, Winseln etc. notirt. Jedenfalls scheint bei einem Gehalt unter 0,03 Proc. die Narkose unvollständig zu sein, da in Vers. X b bei 0,02 Proc. das Thier sehon wieder erwacht war.

Bei einem Gehalt von 0,05 bis 0,07 Proc. Chloralhydrat im Blute schwindet bei Hunden der Cornealreflex vollständig. Gleichzeitig ist bei einem Gehalte von 0,056 Proc. der Blutdruck auf $40-50 \mathrm{~mm} \mathrm{Hg}$ gesunken, wie aus Vers. IX hervorgeht. Bei dieser Giftconcentration war bei langsamer intravenöser Zufuhr auch der Cornealreflex vollständig verschwunden. Bei der Einführung des Chloralhydrats in den Magen verschwand hingegen in Vers. $\mathrm{X}$ der Cornealreflex erst bei 0,07 Proc. und die gleiche Grenze ergab sich 
Ueber die Vertheilung des Chloralhydrats und Acetons im Organismus. 363

auch bei der genaueren Verfolgung dieses Symptons in Vers. VI, in welchem nach der Einführung von $0,5 \mathrm{~g}$ pro Kilo per os der Cornealreflex nach 90 Minuten bei 0,076 Proc. im Blute eben verschwunden war, um nach 122 Minuten bei 0,07 Proc. ganz sehwach wiederaufzutreten.

Bei einem Gehalt von 0,11 bis 0,12 Proc. im Blute tritt beim Hunde der Respirationsstillstand ein. So erfolgte in Vers. IV nach subcutaner Injection von $0,5 \mathrm{~g}$ pro Kilo Athmungs- und bald darauf Herzstillstand bei 0,12 Proc. im Blute und auch bei langsamer intravenöser Einführung des Giftes in Vers. V und Vers. VIII wurde der Chloralgehalt im Blute zu 0,123 Proc. resp. zu 0,113 Proe bestimmt, als der Athemstillstand eben eingetreten war, während das Herz nach Einleitung künstlicher Respiration noch gut weiterschlug. Auch in Vers. III war die Athmung nach Einführung des Giftes vom Magen aus bei 0,11 Proc. ungemein langsam und vom Athemstillstand nicht mehr sehr weit entfernt. Bei einem Gehalte von 0,07 bis 0,08 Proc. geht die Athmung hingegen noch ausreichend gut vor sich (Vers. VI und $\mathrm{X}$ ); nur in Vers. IX trat der Respirationsstillstand bei intravenöser Injection schon bei 0,074 Proc. ein, doch handelte es sich in diesem Fall um ein Thier, welches einige Stunden zuvor $6 \mathrm{mg}$ Morphin pro Kilo erhalten hatte.

Wir können somit die bei der Chloralhydratnarkose im Blute von Hunden ermittelten Werthe dahin zusammenfassen, dass bei 0,03 bis 0,05 Proc. Narkose eintritt, bei 0,05 bis 0,07 Proc. der Cornealreflex verschwindet und bei etwa 0,11 bis 0,12 Proc. der Respirationsstillstand erfolgt. Bei dem gegen die Chloralnarkose ungleich resistenteren Kaninchen (Vers. I und II) geht hingegen die Athmung bei einem Gehalte von 0,14 Proc. Chloralhydrat im Blute noch gut vor sich und beginnt erst bei 0,156 Proc. zu versagen.

Vergleichen wir nun die bei der Verblutung der Versuchsthiere im Blute anfgefundenen Werthe mit dem Gehalt an Chloralhydrat, welchen das Gehirn aufweist, so lässt sich auch aus der kleinen Anzahl von 9 Versuchen, in denen Blut und Gehirn gleichzeitig untersucht wurden, einiges Bemerkenswerthe entnehmen.

In der ersten Zeit nach der Einführung grosser Gaben Chlorallydrat bleibt sowohl bei der Resorption vom Magen aus, als nach subcutaner und intravenöser Injection der Giftgehalt des Gehirns immer gegen den des Blutes zurẗck. Einige Zeit nach Beendigung der intravenösen Zufuhr oder bei der Abnahme des Resorptionsstroms einige Stunden nach der Einführung in den Magen sinkt aber der Chloralhydratgehalt des Blutes stärker ab, als der des Gehirns. 
Dann finden wir das Gehirn relativ giftreicher. Deshalb schwanken die Gehirnwerthe in der Tabelle viel weniger, als die im Blute in verschiedenen Stadien der Vergiftung ermittelten Procentzahlen.

So ist bei den Kaninchen (Vers. I und II), welche auf der Höhe der Vergiftung verblutet wurden, das Blut weit reicher an Chloralhydrat, als das Gehirn. Auch bei den Hundeversuchen bleibt in jenen Fällen, in denen grosse Gaben rasch zugeführt wurden, das Gehirn auf der Höhe der Vergiftung hinter dem Giftgehalt des Blutes zurück. Ist aber nach Einführung der gleichen Dosis längere Zeit verstriohen, so erreicht die Gifteoncentration im Gehirn jene im Blute oder übertrifft sie sogar. Es scheint also, dass im Wettbewerb der Affinitäten in Blut und Gehirn das letztere nicht so rasch im Stande ist, sich mit Chloralhydrat anzureichern; erst ein allmählicher Ausgleich lässt ein gewisses Anziehungsvermögen des Gehirns dem Narkoticum gegenüber hervortreten. Am besten geht dies aus dem Vergleiche von Ver's. III und VI hervor. Beide Hunde hatten $0,5 \mathrm{~g}$ Chloralhydrat pro Kilo per os erhalten; in Vers. III erwies sich 25 Minuten nach der Einftuhrung das Blut weit reicher an Gift, als das Gehirn. In Vers. VI aber hat sich $2^{1 / 2}$ Stunden nach der gleichen Dosis das Verhältniss wesentlich geändert; das Gehirn enthält nunmehr mehr Chloralhydrat als das Blut. Ebenso war in Vers. V, als nach intravenöser Zufuhr einer zum Athmungsstillstand führenden Dosis 37 Minuten lang bei künstlicher Respiration gewartet wurde, bis der Hund wieder selbstständig zu athmen begann, das Nervengewebe nicht unerheblich giftreicher, als das Blut, und unter ähnlichen Verhältnissen kam in Vers. VIII der Chloralhydratgehalt des Gehirns wenigstens dem des Blutes gleich.

Der Vergleich von Blut und Gehirnzahlen führt somit zu dem Resultat, dass das Nervengewebe das Gift aus dem Blute relativ langsam anzieht, dafür aber nach dem Absinken der Giftconeentration im Blute auch länger festzuhalten vermag. Daher kann das Gehirn in gewissen Stadien der Narkose mehr Chloralhydrat enthalten als das Blut.

In ähnlicher Weise dringt nach den Versuchen von Overton ${ }^{1}$ ) das Chloralhydrat aus der Aussenflüssigkeit auch relativ langsam in Kaulquappen ein, welche in der Lösung schwimmen. Nach Ueberführung der Thierchen in reines Wasser kann aber die Narkose noch 2-3 Stunden lang bestehen bleiben. Auch bei diesen Versuchsthieren muss das Gift demnach auffallend lange in Blut oder Geweben festgehalten werden.

1) Overton, a. a. O. S. 107. 
Ueber die Vertheilung des Chloralhydrats und Acetons im Organismus. 365

Für die Betrachtung der Frage, ob sich ein Aufspeicherungsvermögen des Nervensystems für Chloralhydrat nachweisen lässt, muss der Giftgehalt des Gehirns aber nicht bloss mit dem des Blutes sondern auch mit dem anderer Organe verglichen werden. Deshalb wurde die Bestimmung auch in der Leber ausgeführt. Die beztiglichen Zahlen seien in der folgenden Tabelle zusammengestellt.

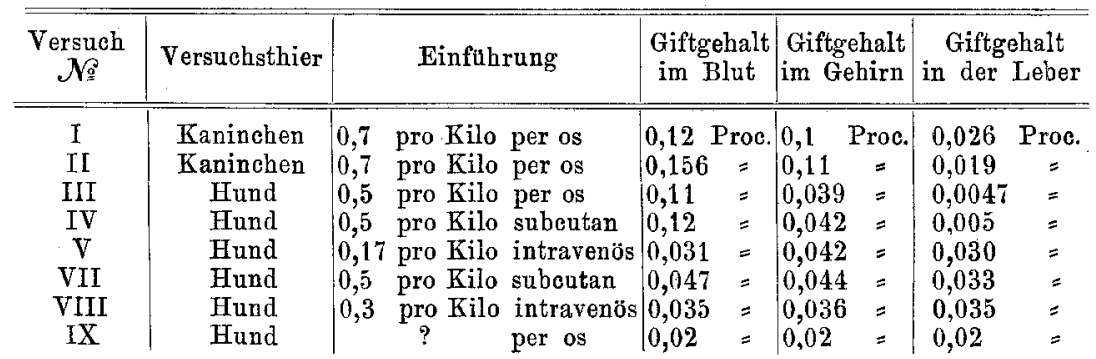

Der Gehalt der Leber an Chloralhydrat bleibt in allen Fällen mehr oder weniger erheblich hinter dem des Gehirns zurück. Nur in Versuch VIII und IX kommt er dem Gehirnwerth gleich. Diese Zahlen sind aber nicht ohne Einschränkung für weitere Ueberlegungen verwendbar; denn, wie schon bei den methodischen Versuchen bervorgehoben wurde, sind die in der Leber erhaltenen Werthe nur als Maximalwerthe zu betrachten, da auch die von Chloralhydrat freie Leber bei der zur Bestimmung verwandten Methode Substanzen liefert, die gleich der aus dem Chloralhydrat abgespaltenen Ameisensäure Sublimat zu Calomel reduciren. Die für die Leber angeführten Zahlen können demnach unter Umstänđen bis um 4 bis $8 \mathrm{mgr}$ pro 100 Leber zu hoch ausfallen. Keinesfalls aber sind sie zu niedrig. Man dürfte deshalb nicht fehlgehen, wenn man die niedrigeren Werthe als die richtigeren ansieht und die höheren nur als Maximalzahlen gelten lässt. Dann erscheint aber der Unterschied der Gifteoncentration in den beiden Organen noch erheblicher.

Der Vergleich zwischen Gehirn und Leber spricht somit für eine specifische physikalisch-chemische Affinität des Centralnervensystems für das Narkotieum; dieselbe tritt aber bei der Vergiftung in Wettbewerb mit anderen Affinitäten im Blute. Auch für das Blut liess sich feststellen, dass das Chloralhydrat darin nicht einfach gelöst, sondern ganz analog dem Verhalten des Chloroforms und Aethers vornehmlich an die rothen Blutkörperchen gebunden ist. Nach dem Auffangen der Blutprobe in einem Salzgemisch von Kochsalz und oxalsaurem Natron und 24 stïndigem Absitzen fand 
sich das Gift nicht gleichmässig in der oberen abgeheberten Serumschicht und den unteren Schichten vertheilt, sondern die unten stehende Serumsalzmischung, die den Blutkörperehenbrei enthielt, war ungleich reicher an Chloralhydrat.

$43 \mathrm{~g}$ Blut eines tief chloralisirten Hundes (Vers. VII) werden mit Kochsalz-Natriumoxalatlösung auf $316 \mathrm{~g}$ gebracht, nach 24 stündigem Stehen die oberen Serum-Salz-Schichten von der unteren Blutkörperchen-Schicht abgetrennt.

$215 \mathrm{~g}$ Serum-Schichten entsprechen $29,9 \mathrm{~g}$ des angewandten Blutes und enthalten $0,0106 \mathrm{~g}$ Chloralhydrat $=0,032$ Proc. des Blutes.

$101 \mathrm{~g}$ Blutkörperchen-Schicht entspricht $13,6 \mathrm{~g}$ des angewandten Blutes und enthalten $0,098 \mathrm{~g}$ Chloralhydrat $=0,066$ Proc. des Blutes. Nach dem Gehalte der Serum-Schichten wäre in der BlutkörperchenSchicht nur $0,005 \mathrm{~g}$ zu erwarten; dieselbe ist aber doppelt so reich an Chloralhydrat.

Wir müssen also für das Chloralhydrat wie für Chloroform und Aether eine specifische Affinität von Zellbestandtheilen der rothen Blutkörper annehmen und werden dieselbe in Analogie mit jenen Fällen in den fettartigen Substanzen suchen. Nächst dem Blute müssen wir aber dem Centralnervensystem ein Bindungsvermögen für Chloralhydrat zuschreiben, weil sich das Gehirn nach längerer Daner der Narkose als giftreicher erweist als das Blut und die Gifteoncentration im Centralnervensystem stets die in der Leber übertrifft. Auch im Centralnerrensystem scheint das Gift keineswegs gleichmässig vertheilt za sein. Wenigstens enthielt in Versuch VII das Rïckenmark auffallender Weise drei Mal mehr Chloralhydrat, als das Gehirn. Da aber das Rückenmark nur in diesem Falle untersueht wurde, können aus dem alleinstehenden Befunde keine weitgehenden Folgerungen gezogen werden.

Der Vergleich des Chloralhydratgehaltes in den versehiedenen Organen lässt allerdings noch einen Einwand zu. Es wäre möglich, dass die Leber dem Blute zwar nieht weniger von dem Narkoticum entnimmt, als das Gehirn, aber im Stande wäre, Chloralhydrat so. rasch in Urochloralsäure umzuwandeln, dass wir nur wenig unverändertes Gift finden. Die Berechtigung dieses Einwands muss zugegeben werden; doch spricht gegen diese Deutung, dass die Leber auch unmittelbar nach intravenöser Zufuhr grosser Giftmengen sehr arm an Chloralhydrat gefunden wurde, und der Umstand, dass bei Aether und Aceton die Verhältnisse ähnlich liegen, obgleich diese Substanzen einer Umwandlung nicht unterliegen. 
Ueber die Vertheilung des Chloralhydrats und Acetons im Organismus. 367

Versuche über die Vertheilung des Acetons.

Von den gleichen Gesichtspunkten aus prïfte ich die Vertheilung des Acetons bei der Narkose durch Inhalation des Giftes. Die geringe toxische Wirksamkeit des Acetons, von dem sich grosse Mengen im Organismus anhäufen können, ohne dass eine deletäre Wirkung auf das Centralnervensystem dem Leben ein Ende macht, lässt diese narkotische Substanz für die Versuche geeignet erscheinen. Die Narkose nach Zufuhr grösserer Acetonmengen verläuft dabei völlig nach dem Typus der Alkohol- und Chloroform-Gruppe.

Als Versuchsthiere dienten Kaninchen. Ich hielt dieselben in einer luftdicht schliessenden Glasglocke, durch welche mit Acetondämpfen beladene Luft hindurchgesaugt wurde, eine Anordnung; die schon Ruschhaupt ${ }^{1}$ ) in einer früheren Arbeit zur Vergiftung: benützt hatte. Nach versehieden langer Zeit nach Beendigung: der Vergiftung wurden die Thiere verblutet und der Acetongehalt in Blut, Gehirn und Leber bestimmt.

Die Acetonbestimmungen wurden nach der titrimetrisehen Methode ron Messinger ausgeführt und dabei im Einzelnen folgendermaassen verfahren:

Blut und die grob zerkleinerten Organe wurden 3 bis 5 Stunden lang mit viel Wasser destillirt und dabei das Destillat zur Vermeidung von Verlusten sorgfältig aufgefangen; ich liess die Luft aus der Vorlage noch durch ein kleines Kölbehen mit Wasser streichen, dessen Inhalt dem Destillate später zugefügt wurde. Um das Stossen bei der Destillation zu vermeiden, bewährte es sich am besten, Blut mit Zusatz einiger Tropfen Essigsäure zu destilliren; die Organe hingegen wurden unter Zusatz $30 \%$ iger Natronlange gekocht und destillirt. Das erste Destillat wurde jedesmal zum zweiten Male destillirt und zwar immer unter Zusatz von etwas Schwefelsäure. ${ }^{2}$ ) Im zweiten Destillate wurde sodann die Bestimmung nach Messinger ausgeführt.

Da nach den Untersuchungen von Jakseh's ${ }^{3}$ ) sich auch im normalen Blut Spuren jodoformbildender Substanz finden und derselbe Autor auch in den Destillaten von Leber, Milz und Nieren geringe Jodoformreaction nachwies, so war bei den Bestimmungenstets ein kleiner Fehler zu erwarten. Ich selbst konnte bei Einhaltung des geschilderten Verfahrens aus $40 \mathrm{~g}$ normaler Leber ohne

1) Ruschhaupt, Dieses Archiv. Bd. XLIV.

2) Vgl. Huppert, Analyse des Harns. Wiesbaden 1898. S. 763.

3) v. Jaksch, Zeitschrift f. klin. Medicin. Bd. VIII. S. 115. 
Zusatz von Aceton 0,003 gr Aceton resp. jodoformbildender Substanz im Destillate finden. Da es sich in den folgenden Versuchen um die Vertheilung der recht grossen Mengen von Aceton handelt, deren Zuführung erst Narkose hervorruft, so erschien der Fehler, welchen die geringen Mengen jodoformbildender Substanz in normalen Organen verursachen, verschwindend klein. Die nach der Narkose erhaltenen Werthe bewegen sich stets in Zehntel-Procenten, ja überschreiten häufig $1 / 2 \%$, während der normale Gehalt der Organe an jodoformbildender Substanz nur Tausendstel-Procent beträgt.

Für die Branchbarkeit der Methode zur Entscheidung der in unseren Versuchen aufgeworfenen Fragen sprechen die folgenden Kontrollversuche.

1. Versuch. $42 \mathrm{~g}$ frisches Katzenblut werden mit 10 Tropfen Essigsäure und $0,1164 \mathrm{~g}$ Aceton versetzt and zweimal mit viel Wasser destillirt.

Zugesetzt: $0,1164 \mathrm{~g}$ Aceton gefunden: $0,114 \mathrm{~g}$ Fehler: $-2,4 \mathrm{mg}=2$ Proc.

2. Versuch. $35 \mathrm{~g}$ Rindsblut werden mit 6 Tropfen Essigsäure und $0,0542 \mathrm{~g}$ Aceton versetzt und zweimal destillirt.

Zugesetzt: $0,0542 \mathrm{~g}$ Aceton gefunden: $0,055 \mathrm{~g}$

Fehler: $+1,3 \mathrm{mg}=1,5$ Proc.

3. Versuch. $72 \mathrm{~g}$ grob zerkleinerter Leber werden mit $10 \mathrm{cem} 30$ proc. $\mathrm{KOH}$ und $0,0423 \mathrm{~g}$ Aceton versetzt und wie oben zweimal destillirt.

$$
\begin{gathered}
\text { Zugesetzt: } 0,0423 \mathrm{~g} \text { Aceton gefunden: } 0,044 \mathrm{~g} \\
\text { Fehler: }+1,7 \mathrm{mg}=5 \text { Proc. }
\end{gathered}
$$

4. Versuch. $30 \mathrm{~g}$ Gehirnbrei werden mit $10 \mathrm{cem} 30$ procentiger $\mathrm{KOH}$ $+0,0725 \mathrm{~g}$ Aceton versetzt und zweimal mit Wasser destillirt.

Zugesetzt: $0,0725 \mathrm{~g}$ Aceton gefunden: $0,0708 \mathrm{~g}$ Fehler: $-1,7 \mathrm{mg}=2,3$ Proc.

Ueber die Vertheilung des Acetons nach der Narkose durch Inhalation des Gifts liegt schon eine gelegentliche Angabe von v. Jaksch vor. v. Jakschi) studirte die Symptome acuter Acetonvergiftung an Katzen und bestimmte in zwei Fällen den Acetongehalt in den Organen der nach der Inhalation verstorbenen Thiere. Die Versuchsthiere wurden hier nicht verblutet; da das Blut viel Aceton enthält, so mussten die blutreichen Organe auch reich an Aceton erscheinen. Dennoch ergaben die Bestimmungen in beiden Fällen das bemerkenswerthe Resultat, dass das Gehirn, also ein relatir blutarmes Organ, die stärkste Gifteoncentration aufwies. In dem einen Falle übertrifft allerdings der Acetongehalt des Gehirns den der Leber nur wenig $(0,16 \%$ im Gehirn, $0,15 \%$ in

1) v. Jaksch, Zeitschrift f. klinische Medicin. Bd. X. 1885. 
Ueber die Vertheilung des Chloralhydrats und Acetons im Organismus. 369

der Leber, 0,12\% in der Niere, $0,09 \%$ in der Lunge); im zweiten Falle jedoch ist das Aceton in den ubrigen Organen ziemlich gleichmässig vertheilt und nur das Gehirn ist auffallend acetonreicher $(0,610 \%$ im Gehirn, $0,1 \%$ in der Leber, $0,115 \%$ in der Lunge, $0,1 \%$ in der Niere).

Die von mir angestellten Versuche über die Vertheilung des Acetons lassen sich in Form einer Tabelle wiedergeben.

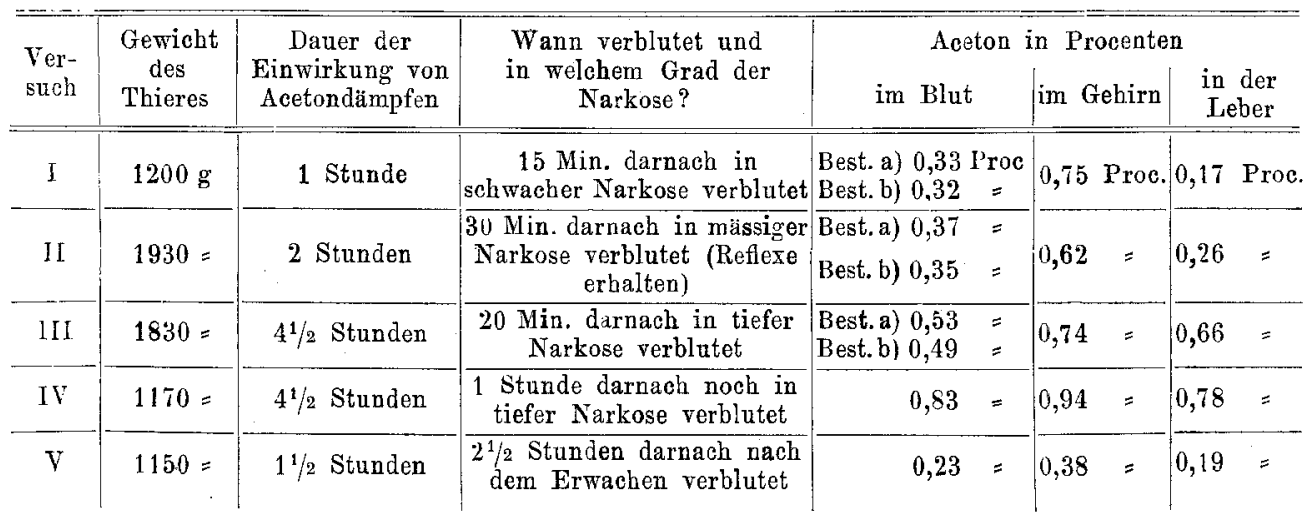

Bei der gewählten Versuchsanordnung war der Acetongehalt der Organe und parallel damit die Schwere der Vergiftung im Momente der Verblutung abhängig von der Aufnahme des Giftes bei der Inhalation, also von dem Partiardruck der Acetondämpfe in der Glocke und der Dauer des Aufenthalts in derselben, und andrerseits von der Zeit, welche seit der Entfernung der Thiere aus der Acetonatmosphäre bis zur Verblutung verstrich und der Ausscheidung des Giftes während derselben. Dabei war bei der geringen Giftwirkung des Acetons eine länger dauernde Zufuhr reichlicher Acetondämpfe erforderlich, um tiefe Narkose herbeizufübren; auch geht bei kurzdauernder Einwirkung die Ausscheidung so rasch von statten, dass die Thiere verhältnissmässig bald wieder aus der Narkose erwachen, nach längerem Aufenthalt in der Glocke dauert die Narkose aber noch stundenlang an.

In Uebereinstimmung mit dieser schwachen narkotischen Wirkung steht die Höhe des Acetongehaltes, bis zu der das Gift im Gehirn aufgespeichert werden muss, ehe tiefe Narkose eintritt. Bei einem Gehalt von $0,23 \%$ Aceton war das Kaninchen in Versuch V schon wieder erwacht; tiefe Narkose fand sich erst von 0,5 Proc. an. Für das Studium der Vertheilung ist diese Anhäufung relativ grosser und daher gut bestimmbarer Mengen günstig. Neben dem Gehirn 
wurden Blut und Leber verschieden lange Zeit nach der Entfernung: der Thiere aus der Acetonathmosphäre auf ihren Acetongehalt untersucht. Aus der Tabelle der Versuche geht hervor, dass sich die neurotrope Natur des Narcoticums sehr deutlich in der Vertheilung ausspricht. Das Gehirn enthält in allen Fällen mehr Aceton, als das Blut, und zwar ist bei sehwacher Narkose die Differenz der Procentgehalte eine grössere, als in tiefer Vergiftung. Im Wettbewerb der Affinitäten zieht das Centralnervensystem das Gift somit stärker an. So ist das Gehirn in Versuch I bei schwacher, nicht bis zum Verschwinden der Reflexe fortgesetzter Narkose fast doppelt so acetonreich, als das Blut, während die Differenz in sehr tiefer Narkose (Versuch III und IV) eine weit geringere ist. Klingt die Giftwirkung bei der Ausseheidung des Acetons wieder ab, so verschwindet das Gift aus dem Blute schneller, als aus dem Gehirn, so dass bei der Erholung aus sehr tiefer Narkose in Versuch V der Acetongehalt des Gehirns den des Blutes wieder weit übertrifft. Das Centralnervensystem hält das Narcoticum demnach auch läng'er fest.

Diese Resultate werden durch einen Vergleich von Gehirn und Leber ergänzt. In allen Fällen ist das Gehirn auch giftreicher, als die Leber, ja der Acetongehalt der Leber bleibt sogar meist hinter dem des Blutes etwas zurïck; nur in Versuch III ist er höher. Vor allem aber sinkt die Giftconcentration in der Leber beim Abklingen der Vergiftung zugleich mit der Ausscheidung des Acetons aus dem Blute; die Leber hält dar Gift nicht zurüok, wie dies das Gehirn vermag.

Die Affinität des Centralnervensystems zu der narkotisehen Substanz tritt demnach bei der Acetonvergiftung ungemein deutlich hervor. Dass wir dieses Bindungsvermögen in einer meehanischen Affinität der fettartigen Substanzen zum Gifte suchen müssen, geht daraus hervor, dass auch die Vertheilung des Acetons zwischen Serum und Blutkörperchen im Blute den gleichen Gesetzen folgt, wie die des Chloroforms, Aethers und Chloralhydrats. Wurde das Blut in einer Mischung von Kochsalz- und Natriumoxalatlösung aufgefangen und 24 Stunden stehen gelassen, so dass sich die oberen Schichten der reinen Serum-Salz-Misehung von der unteren Schicht gut abheben liessen, welche die Blutkörperchen enthielt, so erwies sich die Blutkörperchenschicht als procentisch reicher an Aceton, als die abgehobenen Serumsehichten. Das Aceton circulirt demnach im Blute nicht gleichmässig vertheilt, sondern ist wie das Chloroform vornehmlich an die rothen Blatkörperchen gebunden. 
Ueber die Vertheilung des Chloralhydrats und Acetons im Organismus. 371

Ein Versuchsbeispiel möge dieses Verhalten illustriren.

In Versuch $V$ wurde das bei der Verblutung entnommene Blut in 2 Portionen getheilt. gefunden.

In 26,1 g Blut (Probe I) werden 0,097 g Aceton $=0,37$ Proc.

$29,2 \mathrm{~g}$ Blat (Probe II) werden mit $200 \mathrm{cem} \mathrm{NaCl-Lösung} \mathrm{und} 4 \mathrm{ccm}$ Natriumoxalat-Lösung versetzt und die oberen Serum-Salzschichten nach 24 Stunden von der Blutkörperchenschicht abgetrennt.

Die oberen Serumschichten entsprechen $25,2 \mathrm{~g}$ des angewandten Blutes und enthalten $0,073 \mathrm{~g}$ Aceton $=0,29$ Proc.

Die Blutkörperchenschicht entspricht $4,0 \mathrm{~g}$ des angewandten Blutes und enthält $0,028 \mathrm{~g}$ Aceton $=0,76$ Proc.

Nach dem Gehalte der Serumschichten wäre in der Blutkörperchenschicht nur $0,012 \mathrm{~g}$ Aceton zu erwarten, dieselbe ist aber mehr als doppelt so reich an Aceton.

Die mitgetheilten Untersuchung'en sind keineswegs ausreichend, um einen vollständigen Einblick in die Vertheilungsgesetze von Chloralhydrat und Aceton in den versehiedenen Stadien ihrer Wirkung zu gestatten. Dennoch ergeben sie Anhaltspunkte für die Annahme eines specifischen Bindungsvermögens des Centralnervensystems für beide Gifte. Beim Aceton spricht sich diese Affinität darin aus, dass das Gehirn mehr von dem Nareoticum enthält, als Blut und Leber, und das Gift auch während seiner Ausscheidung aus dem Blute länger festhält. Das Chloralhydrat dringt zwar nur langsam aus dem Blut in das Centralnervensystem ein, wird aber gleichfalls stärker in demselben festgehalten und bäuft sich daselbst in grösserer Concentration an, als in der Leber. 